\title{
Colocalization of Tyrosine Hydroxylase and Fos in the Male Syrian Hamster Brain Following Different States of Arousal
}

\author{
Stephen E. Asmus * and Sarah Winans Newman ${ }^{\dagger}$ \\ Department of Anatomy and Cell Biology, University of Michigan, Ann Arbor, Michigan 48109-0616
}

\begin{abstract}
SUMMARY
In an investigation of the role that central tyrosine hydroxylase- $($ TH ) containing neurons play in copulation in the male Syrian hamster, the induction of Fos protein was used as an index of neuronal activation. With a double immunoperoxidase technique, the activation of TH neurons was compared in hamsters from three experimental groups: (1) mated in a new cage; (2) handled controls placed into a new cage, and ( 3 ) unhandled controls. Although mating selectively induces Fos production in the medial amygdaloid nucleus (Me), more than half of the $\mathrm{TH}$ neurons in Me (a region outside of the classical catecholamine systems) expressed Fos equally in all of the experimental groups. In the paraventricular hypothalamic nucleus (PVN), TH neurons were activated equivalently in mated and handled control animals compared to unhandled controls. TH neurons in the nucleus of the solitary tract (NST) were also activated in handled control animals, and mating further enhanced
\end{abstract}

\section{INTRODUCTION}

Expression of immediate-early genes is one mechanism cells use to couple extrinsic signals with longterm changes in gene transcription (Morgan and Curran, 1991). The rapid and transient induction of one immediate-early gene, c-fos, has been extensively used as a marker of neuronal activation (Dragunow and Robertson, 1987; Hunt et al.,

Received August 30, 1993; accepted October 22, 1993

Journal of Neurobiology, Vol. 25, No. 2, pp. 156-168 (1994)

(C) 1994 John Wiley \& Sons, Inc.

CCC 0022-3034/94/020156-13

* Present address: Department of Neurosciences, Case Western Reserve University, 10900 Euclid Avenue, Cleveland, $\mathrm{OH}$ 44106-4975.

${ }^{+}$To whom correspondence should be addressed. the level of Fos immunostaining in these neurons above both groups of nonmated animals. Although not quantified, co-localization of Fos and TH was also observed in all experimental groups in the olfactory bulbs and the interfascicular nucleus, and in the horizontal limb of the diagonal band of Broca and the cerebral cortex, regions which contain TH neurons but are not part of the classically described TH cell groups. Few, if any, TH neurons in other catecholaminergic brain regions, such as the substantia nigra and locus coeruleus, produced Fos in any of the experimental groups. These results suggest that TH neurons in the PVN and NST may be activated during different states of arousal, and that nonclassical TH neurons in the amygdala produce high levels of Fos even in unstimulated animals. 1994 John Wiley \& Sons, Inc. Keywords: immediate-early genes, medial amygdaloid nucleus, paraventricular hypothalamic nucleus, nucleus of the solitary tract, catecholamine.
1987; Morgan et al., 1987; Sagar et al., 1988). Neurons presumably activated in response to a given stimulus can be identified using immunocytochemistry for Fos, the protein product of c-fos expression. Because we are interested in the role that central tyrosine hydroxylase- (TH) containing neurons play in copulation in the male Syrian hamster, we have used Fos immunocytochemistry to determine if TH-containing neurons in the male hamster brain are selectively activated during mating.

Tyrosine hydroxylase is the first and rate-limiting enzyme in catecholamine biosynthesis, and catecholaminergic neurons in the hamster brain are found in the same brain regions (Vincent, 1988) as those originally defined in the rat brain (Dahlstrom and Fuxe, 1964; Hokfelt et al., 1984). Additionally, the hamster contains TH-producing neu- 
rons in several brain regions that are outside of these classically described systems (Vincent, 1988). One such area is the medial nucleus of the amygdala (Me) (Davis and Macrides, 1983; Vincent, 1988; Asmus et al., 1992; Asmus and Newman, 1993a,b). This nucleus is critical to mating behavior in the hamster (Lehman et al., 1980; Lehman and Winans, 1982), and many cells in this, as well as other, limbic forebrain regions of the hamster and rat are activated during sexual behavior, as demonstrated using Fos immunocytochemistry (Robertson et al., 1991; Baum and Everitt, 1992; Kollack and Newman, 1992; Wood and Newman, 1993). These previous studies demonstrated an overlapping distribution of TH and Fos immunoreactivities in $\mathrm{Me}$, suggesting that the $\mathrm{TH}$-immunostained neurons in the hamster Me may be activated during mating behavior. In addition to $\mathrm{Me}$, $\mathrm{TH}$-containing neurons in the classical catecholaminergic cell groups may be also involved in this behavior. Several studies have demonstrated that in the male rat forebrain, dopamine synthesis (Ahlenius et al., 1991) and release (Pfaus et al., 1990) increase during sexual behavior, and microinjection of a dopamine antagonist inhibits this behavior (Warner et al., 1991).

We hypothesized, therefore, that $\mathrm{TH}$-producing neurons in Me and elsewhere in the brain may be activated during mating behavior. A variety of stimuli have been shown to induce Fos in TH-containing neurons of a number of catecholamine systems (Ceccatelli et al., 1989; Fritschy et al., 1991; Dun et al., 1993; Narvaez et al., 1993). This activation may influence $\mathrm{TH}$ production because the regulatory region of the rat $\mathrm{TH}$ gene contains an AP-1 binding site (Cambi et al., 1989), and transcription of the TH gene has been reported to be under the control of Fos (Gizang-Ginsberg and Ziff, 1990; Icard-Liepkalns et al., 1992).

To test this hypothesis, the co-localization of $\mathrm{TH}$ and Fos was compared in brains from three groups of male hamsters. Animals in the first group were placed into a new cage and allowed to mate. To control for nonspecific effects of handling and exposure to a new environment, a second group of animals was placed alone into a new cage. Because previous studies have compared the behavioral activation of neurons in mated animals with that in either handled (Baum and Everitt, 1992; Wood and Newman, 1993) or unhandled (Robertson et al., 1991; Kollack and Newman, 1992) control animals, it is unclear what the effects of handling might be on the activation of neurons in the brain. Therefore, a third group of animals, which had been quietly resting in their home cage prior to perfusion, was examined. The Fos immunostaining in the latter group of unhandled controls was presumed to represent basal levels of c- fos expression. In the present study, therefore, the activation of TH-producing neurons was investigated during mating and during different states of arousal.

\section{METHODS}

\section{Animals, Behavioral Testing and Tissue Processing}

Adult male and female Syrian hamsters (Mesocricetus auratus; $90-110 \mathrm{~g}$; Charles River) were housed by sex in groups of three to six per cage in a long-day photoperiod ( $14 \mathrm{~h}$ light $/ 10 \mathrm{~h}$ dark) with food and water available $a d$ libitum.

Fourteen sexually naive male hamsters were divided into three groups: (1) mated $(n=5)$; (2) handled controls $(n=5)$, and (3) unhandled controls $(n=4)$. Mating tests were conducted during the first $4 \mathrm{~h}$ of the dark phase of the illumination cycle. Males were placed into a clean cage near a dim light, and then a receptive female was immediately placed into this cage. During the 10 min mating test, all males displayed multiple intromissions, and all but one male ejaculated. These males remained in the clean cage away from the light until they were perfused $1 \mathrm{~h}$ after the end of the mating session. To induce sexual receptivity, ovariectomized female hamsters were injected s.c. with $10 \mu \mathrm{g}$ of estradiol 48 and $24 \mathrm{~h}$ prior to mating and then with $250 \mu \mathrm{g}$ of progesterone 4-6 $\mathrm{h}$ before mating. Handled control animals were placed into a clean cage alone near a dim light for $10 \mathrm{~min}$, after which their cage was moved away from the light, and they were perfused $1 \mathrm{~h}$ later. Unhandled control animals were removed directly from their home cage for perfusion at the end of the light phase of the illumination cycle. Prior to perfusion, the activity of animals in this group had been monitored unobtrusively for $1 \mathrm{~h}$.

Identification of many of the TH-immunostained neurons in Me requires pretreatment with colchicine (Asmus et al., 1992; Asmus and Newman, 1993a), an axoplasmic transport inhibitor (Dahlstrom, 1968). However, colchicine treatment has been reported to induce Fos in brain-stem catecholaminergic neurons (Ceccatelli et al., 1989) and, therefore, could not be used to examine the normal pattern of Fos immunostaining. Therefore, to increase the sample size of TH-immunoreactive neurons in Me of noncolchicine-treated animals, every section through this region was examined in brains from each of the experimental groups.

All animals were anesthetized with sodium ( $\mathrm{Na}$ ) pentobarbital $(15 \mathrm{mg} / 100 \mathrm{~g}$ body weight, i.p.) and perfused through the ascending aorta with $100 \mathrm{ml}$ of $0.1 M \mathrm{Na}$ phosphate-buffered saline containing $0.1 \% \mathrm{Na}$ nitrite for vasodilation, followed by $250 \mathrm{ml}$ of $4 \%$ paraformalde- 
hyde in $0.1 M$ Na phosphate buffer (NaPB; pH 7.4). Brains were removed and postfixed for $1 \mathrm{~h}$ in the perfusion fixative. Following cryoprotection in $20 \%$ sucrose in $\mathrm{NaPB}$, coronal brain sections $(40 \mu \mathrm{m})$ were collected in $\mathrm{NaPB}$ containing $0.01 \% \mathrm{Na}$ azide and stored at $4^{\circ} \mathrm{C}$.

\section{Immunocytochemistry}

To examine the co-localization of Fos and $\mathrm{TH}$, a double immunoperoxidase technique was used. Free-floating brain sections were incubated with a Fos antiserum ( $1: 500 ; \mathrm{Ab}-2$, Oncogene Sciences) for $16-24 \mathrm{~h}$ at $4^{\circ} \mathrm{C}$, followed by a biotinylated donkey anti-rabbit antiserum (1:100; Jackson ImmunoResearch Labs) for $1 \mathrm{~h}$, both diluted in $0.02 \mathrm{M}$ potassium phosphate-buffered saline (KPBS) containing $0.3 \%$ Triton- $\mathrm{X}$ and $2 \%$ normal rabbit serum, and, finally, with the avidin-biotin horseradish peroxidase complex (Elite Vectastain $\mathrm{ABC}$ kit, Vector Labs) diluted in KPBS with $0.3 \%$ Triton-X for $1 \mathrm{~h}$. Bound peroxidase was visualized by incubating the sections with $0.0125 \%$ diaminobenzidine tetrahydrochloride (DAB; Sigma), $0.015 \%$ nickel chloride $\left(\mathrm{NiCl}_{2}\right)$, and $0.06 \%$ hydrogen peroxide $\left(\mathrm{H}_{2} \mathrm{O}_{2}\right)$ in KPBS for $6 \mathrm{~min}$. This produced a black reaction product in the cell nuclei of activated neurons. These sections were subsequently incubated with the $\mathrm{TH}$ antibody (Incstar) diluted to $1: 10,000$ in KPBS with $0.3 \%$ Triton- $X$ for $16-24 \mathrm{~h}$ at $4^{\circ} \mathrm{C}$, then with goat anti-mouse antiserum (Jackson ImmunoResearch) diluted to 1:100 with KPBS and Triton for $1 \mathrm{~h}$, and finally, with mouse peroxidase anti-peroxidase complex (Jackson) diluted to 1:200 with KPBS containing $0.3 \%$ Triton-X and $4 \%$ normal goat serum for $1 \mathrm{~h}$. Sections were then exposed to DAB as described above except that $\mathrm{NiCl}_{2}$ was omitted from the solution. Immunoreactivity for $\mathrm{TH}$ was thus visualized as lightbrown cytoplasmic staining. Each incubation was preceeded by rinses in KPBS and was conducted at room temperature unless otherwise noted. To control for variation in immunocytochemistry, sections from each of the experimental groups were processed simultaneously. Immunostained sections were mounted onto gelatincoated slides, dehydrated, cleared with xylenes, and coverslipped with Permount. Cresyl violet-stained sections were examined for cytoarchitectural identification of the location of TH and Fos immunolabeled neurons.

The rabbit Fos antiserum ( $\mathrm{Ab}-2$; Lot 3922202 ) used in this study was raised against the amino terminus (amino acids 4-17) of the human Fos protein (Van Straaten et al., 1983) and recognizes c-Fos, Fos-related antigens, and the Fos-Jun heterodimer (Oncogene Sciences). Fos immunostaining was eliminated by either omission of the primary antiserum or preincubation of this antiserum with $0.6 \mu M$ Fos peptide (peptide-2, Oncogene Sciences) (Kollack and Newman, 1992). The monoclonal TH antibody (Incstar) was generated in mouse against $\mathrm{TH}$ purified from $\mathrm{PC}-12$ cells and has been shown to react specifically with TH (Wolf et al., 1989).

\section{Data Analysis}

Using bright-field illumination, the immunostained sections were first analyzed qualitatively for Fos immunoreactivity to ensure that mating induced a similar pattern of neuronal activation to that reported previously in the hamster (Kollack and Newman, 1992; Wood and Newman, 1993). Neurons doubly labeled for Fos and TH contained black nuclei surrounded by reddish-brown cytoplasm in the same focal plane, as illustrated in Figure 1. The total number of TH-immunostained neurons and the number of doubly labeled cells were counted bilaterally in every section through the posterodorsal subdivision of $\mathrm{Me}$ (MePD) in four brains from each of the experimental groups. The extent of double-labeling was also noted in brain regions other than MePD, and the paraventricular hypothalamic nucleus (PVN) and the nucleus of the solitary tract (NST) were chosen for quantitative analysis due to the substantial number of neurons in these nuclei displaying co-localization of Fos and TH. In the PVN, the total number of $\mathrm{TH}$-immunoreactive neurons and the number of cells containing both TH and Fos were counted bilaterally within a $0.052 \mathrm{~mm}^{2}$ area at $120-\mu \mathrm{m}$ intervals in the parvicellular region of the ventral PVN. The medial edge of the ocular grid was placed adjacent to the third ventricle, and the ventral edge was aligned with the ventral extent of the PVN. The majority of the doubly labeled cells in the PVN were present within this area. The co-localization of $\mathrm{TH}$ and Fos in the NST was examined by counting all TH-immunolabeled and doubly labeled cells at $120-\mu \mathrm{m}$ intervals throughout the subdivisions of the caudal part of this nucleus, at rostrocaudal levels extending from the obex to the caudal boundary of the area postrema.

From these data, the percentage of TH-immunostained neurons containing Fos-immunoreactive nuclei was determined for each region per brain. The mean percentages $( \pm$ S.E.M.) were compared in mated, handled control, and unhandled control animals by a oneway analysis of variance with post-hoc pairwise comparisons (Scheffe F-test). A $p$ value of less than 0.05 was considered significant.

\section{RESULTS}

\section{General Observations on Fos and TH Immunostaining}

Compared to handled and unhandled controls, the brains of mated animals displayed a substantial increase in the number of Fos-immunoreactive cell nuclei in several discrete brain regions, including the corticomedial amygdala [Fig. 2(A)], BNST, MPOA, and PVN, as reported previously (Insel and Witt, 1991; Robertson et al., 1991; Baum and Everitt, 1992; Kollack and Newman, 1992; Wood and Newman, 1993). These areas in the brains of 

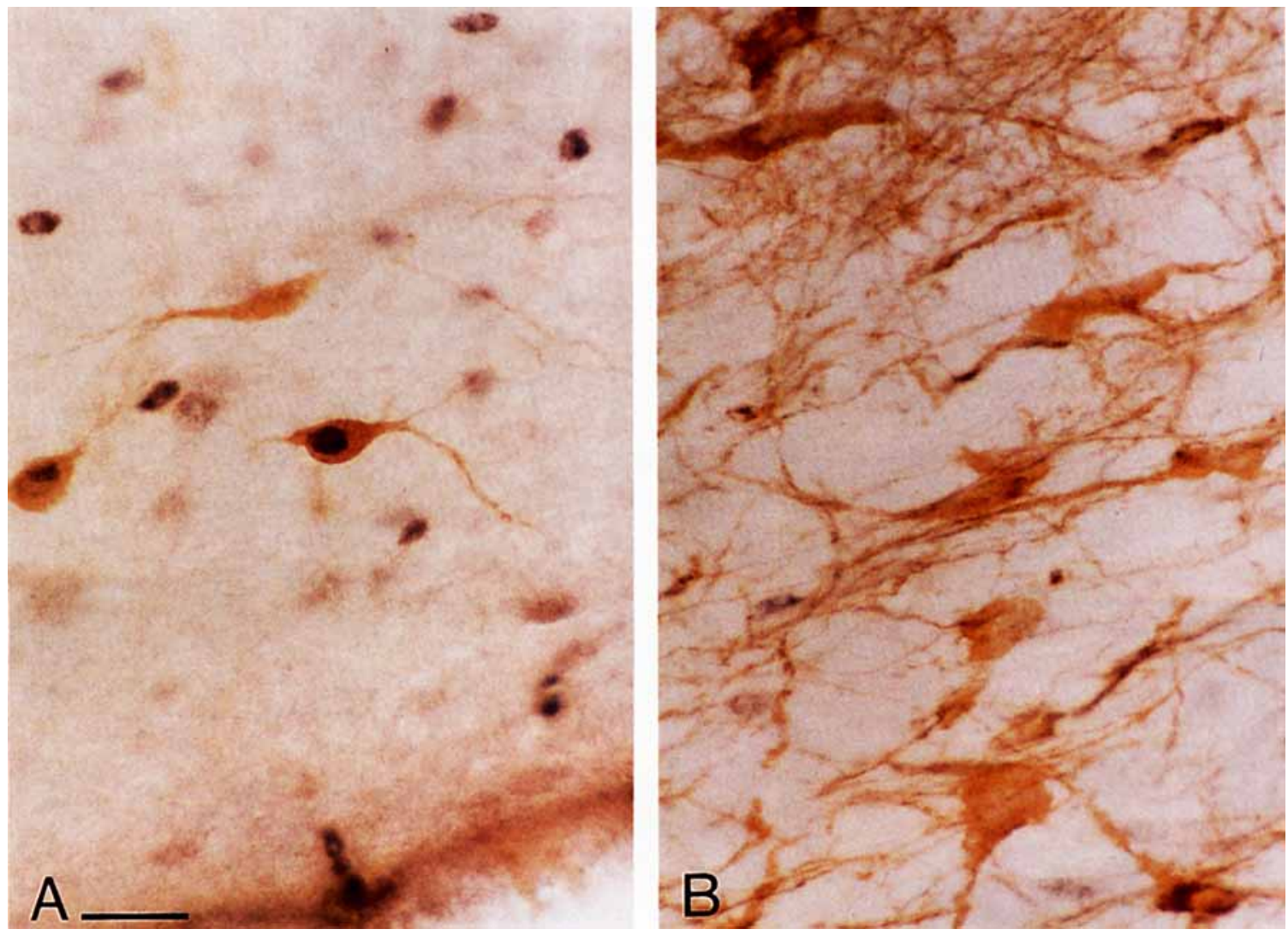

Figure 1 Photomicrographs of neurons immunoreactive for both TH (reddish-brown cytoplasm) and Fos (black nucleus) in the posterodorsal subdivision of the medial amygdaloid nucleus of an unhandled control animal (A), and in the paraventricular hypothalamic nucleus of a handled control animal (B). A neuron immunolabeled for only $\mathrm{TH}$ is seen in the bottom left corner of $\mathrm{A}$. ot $=$ optic tract; $\mathrm{III}=$ third ventricle. Scale bar $=25 \mu \mathrm{m}$.

handled controls contained fewer Fos-immunostained cells, while in unhandled control brains, these areas contained only a few scattered Fos-immunostained cells, similar to the unhandled controls of earlier studies (Robertson et al., 1991; Kollack and Newman, 1992).

Neurons doubly labeled for Fos and TH were numerous in several nonclassical and classical THcontaining cell groups. Figure 1 illustrates neurons immunostained for both Fos and TH in Me [Fig. 1 (A)] and in the PVN [Fig. 1 (B)]. Cells immunostained for either antigen alone were also observed in the same brain regions as doubly labeled neurons. Three specific brain regions, Me, PVN, and NST, displayed a high percentage of doubly labeled cells in one or more of the treatment groups. For each of these areas, we determined the distribution of TH-immunostained neurons, the pattern of Fos immunostaining in the different experimental groups, and finally, the percentage of TH-immu- nostained neurons containing Fos immunoreactivity.

\section{Co-localization of TH and Fos in the Medial Amygdaloid Nucleus}

In the noncolchicine-treated animals used in the present study, the caudal region of the posterodorsal subdivision of Me, as defined by Gomez and Newman (1992), contained a consistent number of TH-immunoreactive neurons [Fig. 2(A)]. The rostro-caudal extent of this cell group was identical to that described previously in animals receiving colchicine (Asmus et al., 1992; Asmus and Newman, 1993a). After immunostaining every section through this area, approximately $60 \mathrm{TH}$-immunoreactive neurons were observed in each brain from the three experimental groups.

The pattern of Fos immunostaining in MePD varied greatly between the groups [Fig. 2(A)], as 
A

MePD

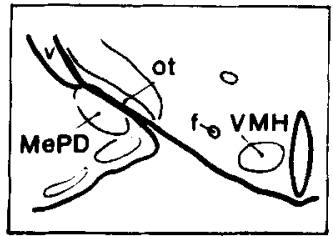

B

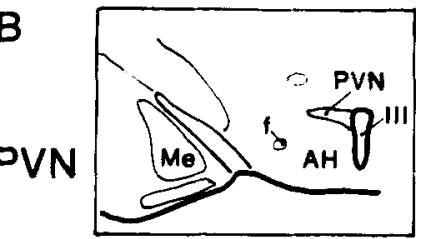

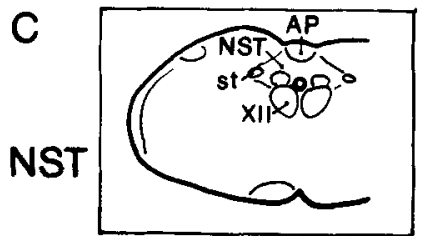
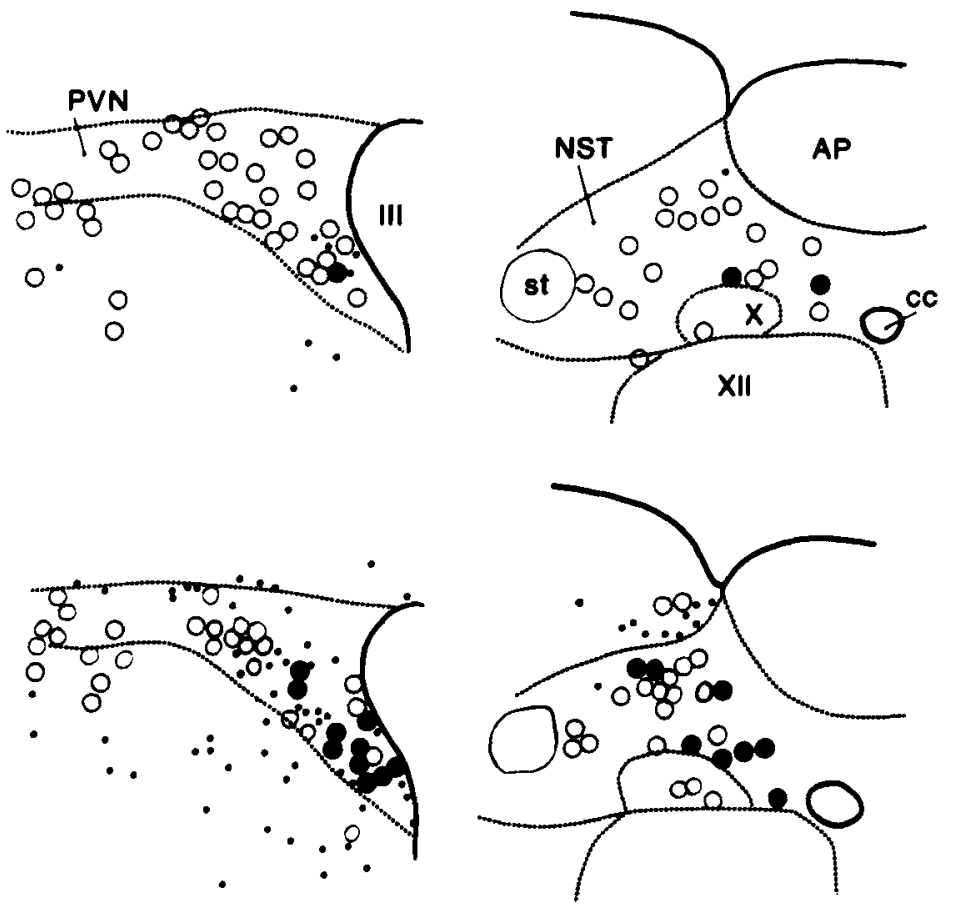

HCon
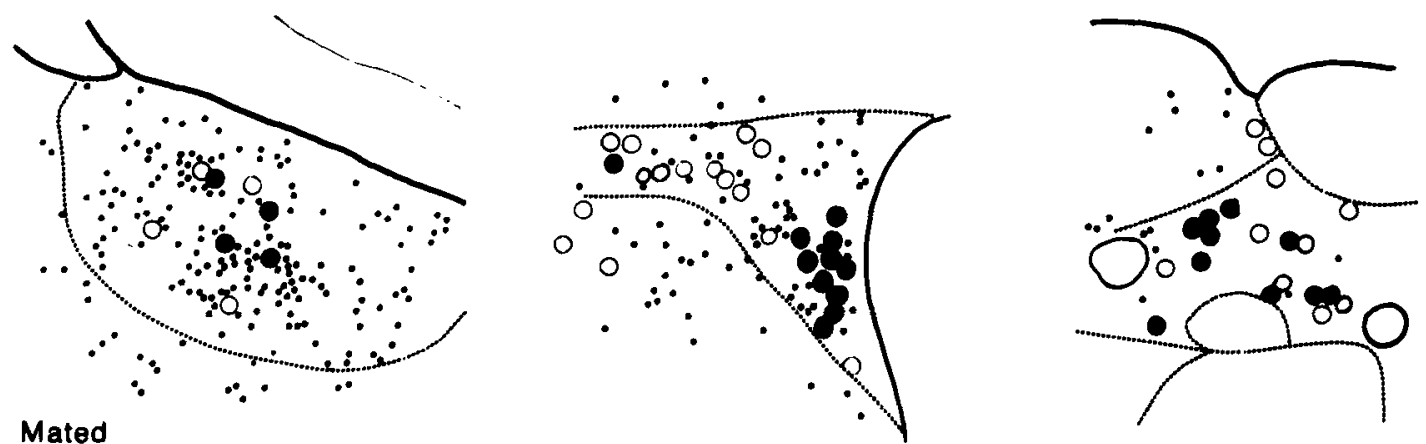

Mated

Figure 2 Cameral lucida tracings of coronal sections through the posterodorsal medial amygdaloid nucleus (MePD) (A), the paraventricular hypothalamic nucleus (B), and the nucleus of the solitary tract (C) of unhandled control (UCon), handled control (HCon), and mated animals. The diagram at the top of each column demonstrates the rostrocaudal level of each area shown. Small dots represent individual Fos-immunoreactive cell nuclei, open circles represent neurons singly labeled for $\mathrm{TH}$, and filled circles represent neurons containing both $\mathrm{TH}$ and Fos immunoreactivities. $\mathrm{AH}=$ anterior hypothalamus; $\mathrm{AP}=$ area postrema; $\mathrm{cc}=\mathrm{cen}$ tral canal; $\mathrm{f}=$ fornix; ot = optic tract; $\mathrm{st}=$ solitary tract; $\mathrm{v}=$ lateral ventricle; $\mathrm{VMH}=$ ventromedial hypothalamic nucleus; $I I I=$ third ventricle; $X=$ dorsal vagal motor nucleus; and XII $=$ hypoglossal nucleus. 
reported previously (Kollack and Newman, 1992; Wood and Newman, 1993). Unhandled controls contained a limited number of Fos-immunolabeled cell nuclei, scattered randomly throughout this subdivision. In handled controls, more cells in this region were labeled for Fos, and mating induced a further increase in this number. Despite these dramatic differences in the pattern of Fos expression, $55 \%-67 \%$ of the TH-immunolabeled neurons in MePD of all three experimental groups also contained Fos immunoreactivity, and no significant differences in the percentage of co-localization were found between the groups [Fig. 3(A)]. Figure $1(\mathrm{~A})$ shows a neuron that is immunoreactive for both TH and Fos in MePD of an unhandled control animal.

\section{Co-localization of TH and Fos in the Paraventricular Hypothalamic Nucleus (A14)}

The analysis of the distribution of TH- and Fos-immunolabeled cells in subdivisions of the PVN is based on the nomenclature of Morin and Blanchard (1993). The distribution of TH-immunoreactive neurons corresponded to that previously described in the PVN of the hamster (Vincent, 1988) and rat (Swanson et al., 1981; Hokfelt et al., 1984). As in Me, Fos immunostaining in the PVN was dependent upon the treatment [Fig. 2(B)]. In the brains of unhandled controls, few Fos-immunolabeled cells were present in the PVN. Placing the animals into a new cage generally increased Fos expression in the periventricular and adjacent parvicellular subdivisions of the PVN. Mating, however, induced a further dramatic increase in the number of Fos-immunostained cell nuclei in a separate, specific cluster of cells at the ventrolateral margin of the PVN, as reported previously by Kollack and Newman (1992). This mating-induced cell cluster appeared to be immediately ventrolateral to the medial magnocellular subdivision as defined by Morin and Blanchard (1993).

Co-localization of Fos and TH was observed posteromedial to the Fos immunostained cells induced by mating and was predominantly confined to the periventricular parvicellular and adjacent parvicellular subdivisions in the ventral portion of the caudal half of the PVN [Fig. 2(B)]. Only a few $\mathrm{TH}$-immunostained cells in the posterior magnocellular division were double-labeled in any of the groups. Within the designated sampling area, approximately 70 neurons were immunostained for TH in the PVN of each brain from the experimen-
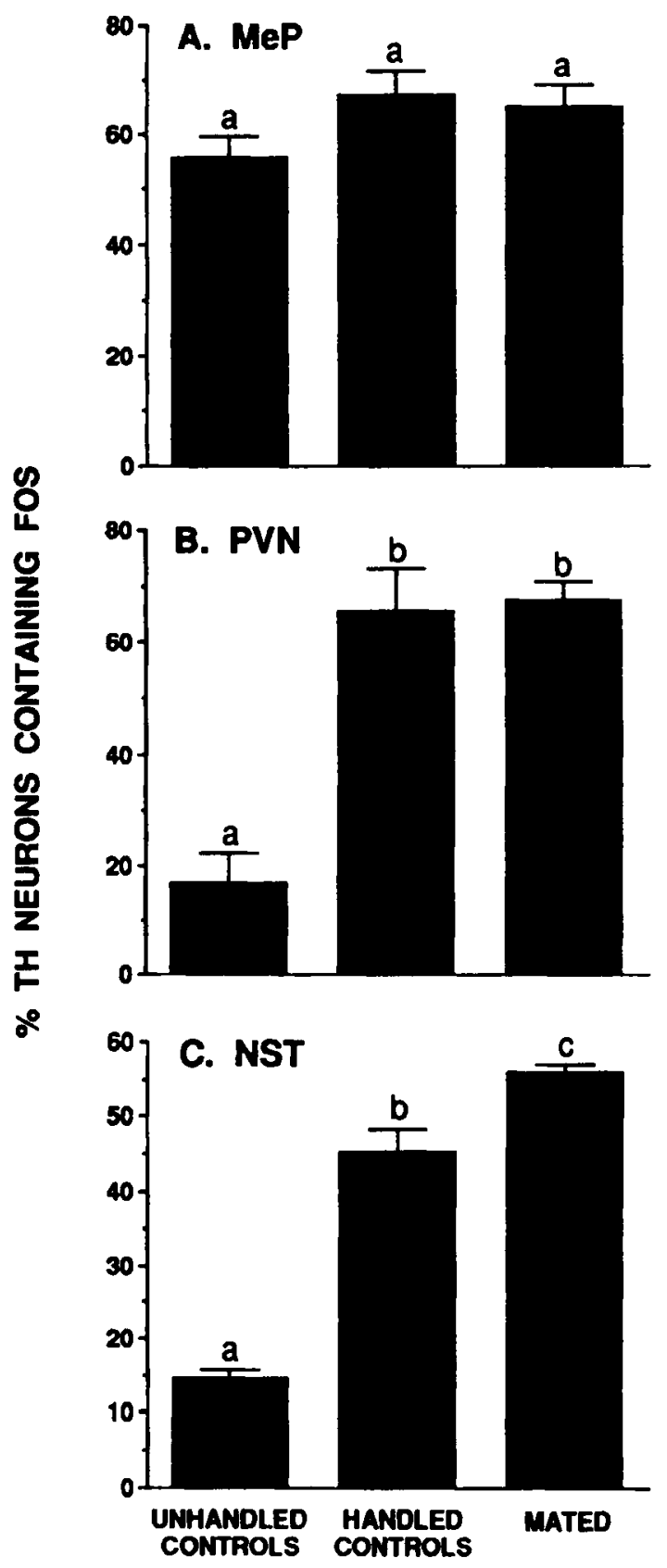

Figure 3 Mean percentage ( \pm S.E.M.) of TH-immunoreactive neurons containing Fos-immunostained nuclei in the posterior medial amygdaloid nucleus (MeP) (A), the paraventricular hypothalamic nucleus (PVN) (B), and the nucleus of the solitary tract (NST) (C) of unhandled control $(n=4)$, handled control $(n=5)$, and mated $(n=5)$ animals. Within each brain region, columns with different superscripts are significantly different ( $p$ $<0.05$ ).

tal groups. In this area, $16.8 \% \pm 5.4 \%$ of the THimmunoreactive neurons in unhandled controls contained nuclear Fos immunostaining [Fig. 
$3(\mathrm{~B})]$. In contrast, a significantly higher percentage of co-localization was observed in this area of handled control $(65.4 \% \pm 7.8 \%)$ and mated $(67.6 \% \pm 3.5 \%)$ animals, and co-localization did not differ significantly between the latter two groups [Fig. 3(B)].

\section{Co-localization of TH and Fos in the Nucleus of the Solitary Tract (A2/C2)}

Neurons immunoreactive for $\mathrm{TH}$ were primarily observed in the caudal region of the NST, at or caudal to the level of the area postrema, similar to the distribution shown previously in the NST of the hamster (Vincent, 1988) and rat (Armstrong et al., 1981; Kalia et al., 1985; Riche et al., 1990). More than $100 \mathrm{TH}$-immunostained neurons were analyzed in the NST of each brain from the experimental groups. Most of the Fos-immunolabeled nuclei were present within $\mathrm{TH}$-containing neurons in all of the experimental groups [Fig. 2(C)]. Unhandled control animals expressed little Fos immunostaining in general, and relative to the other groups, contained a small number of TH-immunoreactive neurons displaying Fos immunoreactivity $(14.5 \% \pm 0.5 \%)$ [Fig. 3(C)]. The percentage of co-localization increased significantly in handled controls $(45.2 \% \pm 3.3 \%)$, and mating further enhanced Fos expression in TH-immunolabeled neurons $(56 \% \pm 1.2 \%)$ to values significantly greater than both groups of nonmated animals [Fig. 3(C)].

\section{Co-localization of $\mathrm{TH}$ and Fos in Other Classical and Nonclassical Catecholamine Cell Groups}

Co-localization of $\mathrm{TH}$ and Fos was noted consistently in numerous periglomerular TH-producing neurons in the main olfactory bulbs (A16) and in the interfascicular nucleus, a dense cluster of cells in the midline of the ventral tegmental area (A10), in all of the experimental groups. However, reliable quantification of the co-localization in these areas was not possible due to the dark TH immunostaining and the dense packing of the cells.

As in MePD, TH-immunostained neurons in the anterior subdivision of $\mathrm{Me}(\mathrm{MeA})$, the horizontal limb of the diagonal band of Broca and the cerebral cortex of the hamster constitute TH cell groups outside of the classical catecholamine systems (Vincent, 1988; Asmus et al., 1992; Asmus and Newman, 1993a,b). Although not quantified due to their limited number per brain, each of these areas displayed coproduction of Fos and TH in all of the experimental groups. Figure 4(A) illustrates a neuron immunostained for both Fos and TH in the horizontal limb of the diagonal band of Broca.

Other brain areas displayed little, if any, co-localization of Fos and TH immunoreactivities regardless of the experimental group. Figure 4(B) provides an example of $\mathrm{TH}$-immunostained neurons that lack Fos in the substantia nigra of a mated animal. Only occasional doubly labeled neurons were seen in the medial preoptic area (A15), the periventricular (A14), and arcuate (A12) hypothalamic nuclei, the periventricular zone of the posterior hypothalamus and thalamus (A11), the nucleus subcoeruleus (A7), and the caudal ventrolateral medulla (A1). Neurons coproducing TH and Fos were almost never seen in any of the treatment groups in the zona incerta (A13), the ventral tegmental area (A10) with the exception of the interfascicular nucleus, the substantia nigra (A9) [Fig. 4(B)], or the locus coeruleus (A6).

\section{DISCUSSION}

\section{General Comments on the Coproduction of Fos and TH in the Hamster Brain}

The present study demonstrates that specific populations of TH-containing neurons in the hamster brain selectively express immediate-early genes during different states of arousal. Depending on the level of stimulation, a range of Fos immunoreactivity was observed in specific TH cell groups. Some TH-synthesizing neurons expressed Fos equally in all of the experimental groups, as in MePD. In the PVN, TH-containing neurons were activated equivalently after the animal had been placed into a new cage or had mated in a new cage. Activation of TH-immunostained neurons in the NST occurred after the animal had been placed into a novel environment, and mating further enhanced the level of Fos immunostaining in these neurons above both groups of nonmated animals. Finally, the majority of TH-immunolabeled neurons throughout the brain did not express detectable levels of Fos in any of the experimental groups investigated here.

The present observation of Fos induction in certain TH-containing neurons suggests that following behavioral activation, $c$ - fos expression may be involved in TH regulation in these specific populations of neurons in the hamster brain. In support of this hypothesis, the regulatory region of the rat $\mathrm{TH}$ 

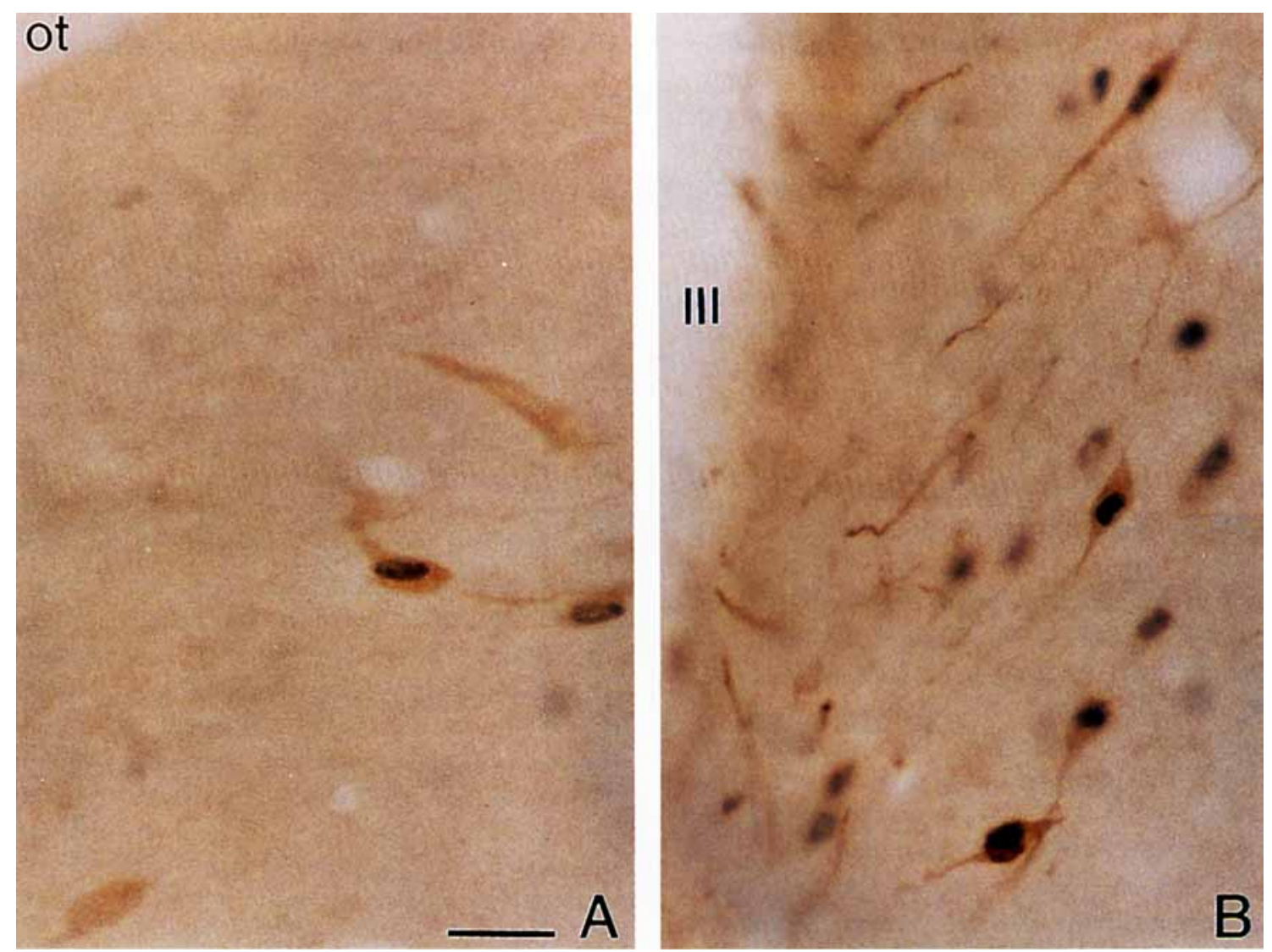

Figure 4 Photomicrographs of neurons immunolabeled for both TH and Fos in the horizontal limb of the diagonal band of Broca from a mated animal (A), and neurons immunoreactive for only TH in the substantia nigra of a mated animal (B). In A, the ventral, pial surface of the brain is at the bottom of the photomicrograph. Scale bar $=25 \mu \mathrm{m}$.

gene has been shown to contain an AP-1 binding site (Cambi et al., 1989), the DNA sequence to which the Fos/Jun heterodimer binds. Moreover, Fos has been implicated in the regulation of $\mathrm{TH}$ gene transcription (Gizang-Ginsberg and Ziff, 1990; Icard-Liepkalns et al., 1992). Thus, if the hamster TH gene contains an AP-1 binding site, the activation of TH-containing neurons following exploration of a new environment and mating in this species may lead to long-term alterations in $\mathrm{TH}$, and, therefore, catecholamine production. $\mathrm{C}$ fos expression may be also involved in the regulation of genes other than, or in addition to, the $\mathrm{TH}$ gene in these cells.

An unexpected finding of the present study was the relatively high levels of Fos immunostaining in specific subsets of TH-immunoreactive neurons in unhandled control animals. Over $50 \%$ of the THimmunostained neurons in MePD, and although not quantified, many of the TH-immunolabeled neurons in MeA, the diagonal band of Broca, and the cerebral cortex contained Fos-immunoreactive cell nuclei in all of the experimental groups. The expression of immediate-early genes in unstimulated brains is not unique to the hamster. Previous studies have demonstrated that a limited number of cells express immediate-early genes in several brain regions of unstimulated rats (Bullitt, 1990; Hughes et al., 1992; Herdegen et al., 1993) and mice (Smeyne et al., 1992). However, the finding of relatively high levels of Fos specifically in THproducing neurons that are outside of the classical catecholamine systems in the brain of unstimulated hamsters suggests that gene transcription in these cells may be regulated by constitutively expressed immediate-early genes. Because the Oncogene Sciences antiserum recognizes Fos-related antigens, as well as Fos, it is possible that Fos-related proteins, which are known to have a more protracted time course of appearance following stimulation compared to Fos (Morgan and Curran, 1991), are expressed in TH-producing neurons of 
unstimulated animals. Regardless of whether these neurons are expressing Fos or Fos-related proteins, immediate-early gene protein products may play a role in the regulation of the basal expression of the $\mathrm{TH}$ gene and/or genes involved in general cellular metabolism. Alternatively, the Fos immunostaining seen in these TH-containing neurons may not be indicative of the presence of a functional transcription factor. Because Jun expression was not examined, it is unknown whether the actual transcription factor AP- 1 is present in these cells.

\section{Co-localization of TH and Fos in the Medial Amygdaloid Nucleus}

Contrary to our original hypothesis, the TH-immunoreactive neurons in MePD were not selectively activated during mating behavior. Many of the TH-containing neurons in this brain region produced Fos even in animals resting in their home cage, and the increase in chemosensory and somatosensory input to this brain region associated with copulatory behavior did not alter Fos expression in this chemically defined subset of cells. Thus, enhancement of both of these inputs, the former via female hamster pheromones (Fiber et al., 1993) and the latter via genital stimulation (Baum and Everitt, 1992), must activate other, yet to be defined, neurons in this brain region.

The absence of mating-induced activation of the TH-containing neurons in MePD could be interpreted to suggest that these cells may not be selectively involved in copulatory behavior. Instead, these neurons may be involved in some other brain function. For instance, the rat Me has been implicated in the regulation of salt intake (Nitibach et al., 1989; Schulkin et al., 1989; Zhang et al., 1993). However, the use of Fos to identify activated neurons has certain caveats. Fos appears to be expressed in response to acute stimuli. The TH-containing cells in MePD, on the other hand, may have a long-term, permissive role in mediating the effects of gonadal steroids on reproductive behaviors. Previous studies have demonstrated that three-fourths of the TH-producing neurons in MePD contain androgen receptors (Asmus and Newman, 1993a), supporting the hypothesis that these neurons play a role in gonadal steroid-dependent behaviors, such as chemoinvestigation (Powers et al., 1985; Havens and Rose, 1992), copulation (Beach and Pauker, 1949; Powers et al., 1985), and aggression (Koolhaas et al., 1990).

\section{Co-localization of TH and Fos in the Paraventricular Hypothalamic Nucleus}

Through its widespread connections with the pituitary gland, the limbic forebrain and autonomic centers in the brain stem and spinal cord, the PVN is known to be a major integrative center that controls homeostatic functions (Swanson, 1987). In spite of the wealth of research on the PVN, little is known about the function of the TH-producing neurons in the parvicellular subdivision of this nucleus in any species. The results presented here suggest that compared to unhandled controls, equivalent numbers of TH-immunostained neurons in the parvicellular PVN were activated both in animals placed into a clean cage alone and in animals that had mated in a clean cage.

The activation of these neurons may be a result of the stress of being handled and placed into a new environment, implicating the TH-containing cells in the hamster PVN in the regulation of the pituitary-adrenal stress axis. Stressful stimuli have been shown to activate cells in the rat PVN (Pezzone et al., 1992). It is also possible that activation of the TH-containing neurons in the PVN may have been simply a response to the increase in physical activity coinciding with exploratory behavior. The handled controls explored the new cage and often hopped along the sides of the cage for the majority of the 10-min testing period. The mated animals were also active throughout the mating session. This increase in activity compared to the controls that were resting quietly presumably increased respiration and cardiac output, thereby stimulating input to the NST via the vagus nerve ( see discussion of NST below). The NST, in turn, sends direct and indirect projections to the PVN (Ricardo and Koh, 1978; Swanson, 1987). Thus, the increase in visceral afferent signals may have transynaptically induced Fos-immunostaining in the TH neurons of the PVN, suggesting a role for these cells in the integration of visceral input to the PVN. Additionally, the arousal associated with being placed into a novel environment may have contributed to the activation of these PVN neurons via projections from limbic forebrain regions (Swanson, 1987).

\section{Co-localization of TH and Fos in the Nucleus of the Solitary Tract}

The NST is a sensory relay center, receiving somatosensory, gustatory and visceral input from the trigeminal, facial, glossopharyngeal, and vagus nerves (Contreras et al., 1982; Kalia and Sullivan, 1982; Whitehead and Frank, 1983). The data pre- 
sented here and in previous studies indicate that the TH-producing neurons in this nucleus, which represent a mixed collection of dopaminergic, noradrenergic (A2) and adrenergic (C2) cells, are confined to its caudal half (Armstrong et al., 1981; Kalia et al., 1985; Vincent, 1988; Riche et al., 1990). These caudal subdivisions of the NST receive cardiovascular, respiratory, and digestive system inputs from the vagus nerve, whereas gustatory input is processed in subdivisions rostral to the obex and, therefore, rostral to the TH-immunolabeled cells examined here (Contreras et al., 1982; Whitehead and Frank, 1983). The activation of the TH-immunostained neurons in the NST observed in the handled control and mated animals was possibly the direct result of increased cardiovascular and respiratory input to this area from the vagus nerve. Additionally, signals from the prefrontal cortex, amygdala, and hypothalamus ( Van der Kooy et al., 1984) areas controlling autonomic function may have played a role in the induction of Fos immunostaining in these TH-containing neurons.

The significant increase in Fos-immunolabeling in the TH neurons in the NST of mated animals above nonmated controls may have been the result of copulation-specific enhancement of visceral and/or forebrain signals to this nucleus. The sympathetic response during reproductive behavior may have increased heart rate and respiration above those in animals simply exploring a new cage, thereby increasing afferent activity to the NST. Furthermore, forebrain areas specifically activated by mating may have induced additional Fos expression in the NST during mating. For example, the PVN was shown to be activated by mating in the hamster (Kollack and Newman, 1992) and rat (Insell and Witt, 1991), and projections from the PVN to caudal NST have been demonstrated in the rat (Van der Kooy et al., 1984). Thus, the TH-immunostained neurons that were activated in the NST of handled control and mated animals may be involved in the central relay of visceral sensory information. In the rat, TH-producing neurons in the caudal NST project to a variety of fore- and midbrain regions (Riche et al., 1990), and catecholamines have been implicated in autonomic transmission (see references in Kalia et al., 1985 and Riche et al., 1990).

\section{Presence or Absence of Fos in Other Classical Catecholamine Cell Groups}

Although not quantified, several other classical catecholaminergic systems expressed Fos. Numerous periglomerular neurons in the main olfactory bulbs were immunolabeled for both TH (A16) and Fos in all three experimental groups. These cells may have been stimulated from (1) olfactory cues in the home cage, (2) the experimenter during handling, (3) clean bedding in the new cage, or (4) in the case of mated animals, from the receptive female. These findings are similar to those of earlier reports of c-fos expression in periglomerular neurons in the rat olfactory bulb after either olfactory stimulation or removal from the home cage compared to animals from an "odor-free" environment (Guthrie et al., 1993). These results support our interpretation that odors present in the home cage of unhandled controls, as well as olfactory stimulation of handled and mated animals, were sufficient to induce Fos production in TH-synthesizing periglomerular neurons of the olfactory bulbs. It is interesting to note that transneuronal input from olfactory receptors has been implicated in the regulation of $\mathrm{TH}$ production in periglomerular olfactory bulb neurons in other rodents (Erlich et al., 1990; Stone et al., 1990).

In the present study, TH-immunostained neurons in another previously described dopaminergic cell group, the interfascicular nucleus (included in A10), displayed Fos immunoreactivity in all experimental groups. The interfascicular nucleus in the rat provides a major component of the mesohabenular pathway (Li et al., 1993), part of the mesolimbic projection system (Bjorklund and Lindvall, 1984). The activation of TH-immunostained neurons here may reflect modulation of limbic-related brain functions.

The majority of classically described catecholaminergic cell groups did not contain Fos immunoreactivity following any of the behaviors examined here. For example, few, if any, of the TH-immunoreactive neurons in the substantia nigra and ventral tegmental area of mated animals expressed Fos. This was surprising in light of the increased nigrostriatal and mesolimbic dopamine transmission that has been demonstrated during sexual behavior in the male rat (Mitchell and Stewart, 1989; Pfaus et al., 1990; Ahlenius et al., 1991). Therefore, although neurons in the hamster substantia nigra and ventral tegmental area are presumed to be receiving and transmitting impulses during copulatory behavior, these neurons do not appear to express Fos under these circumstances. Furthermore, studies in the rat have shown that treatment with reserpine does not induce Fos expression in either of these midbrain regions, whereas other catecholaminergic cell groups produce Fos after this treat- 
ment (Fritschy et al., 1991; Wessel and Joh, 1992). As discussed by Dragunow and Faull ( 1989), some neurons may lack the biochemical phenotype necessary to synthesize Fos. Thus, an absence of Fos immunostaining in a neuron following a specific stimulation or behavior cannot be interpreted as a lack of "activity" of that neuron.

This study has shown that three normal states of arousal, sleeping in a familiar environment, exploring a new environment, and mating, selectively activated TH-producing neurons in specific brain regions of the male hamster. The induction of Fos immunostaining in TH-containing neurons in the PVN and the NST during exploratory and mating behaviors suggests that these cells may play a role in limbic/autonomic integrative mechanisms. In contrast, nonclassical TH-immunoreactive cell groups in several brain areas, including $\mathrm{Me}$, the diagonal band of Broca, and the cerebral cortex, contained relatively high levels of Fos in all of the animals.

The authors gratefully acknowledge the excellent technical assistance of the Morphology Core of the Reproductive Sciences Program at the University of Michigan, supported by NIH 1-P30-HD-18258. This work was supported by NIH Grant NS 20629 to S.W.N.

\section{REFERENCES}

Ahlenius, S., Hillegaart, V., HJorth, S., and LarsSON, K. ( 1991). Effects of sexual interactions on the in vivo rate of monoamine synthesis in forebrain regions of the male rat. Behav. Brain Res. 46:117-122.

Armstrong, D. M., Pickel, V. M., JoH, T. H., Reis, D. J., and MILLER, R. J. (1981). Immunocytochemical localization of catecholamine synthesizing enzymes and neuropeptides in area postrema and medial nucleus tractus solitarius of rat brain. J. Comp. Neurol. 196:505-518.

Asmus, S. E., Kincaid, A. E., and Newman, S. W. (1992). A species-specific population of tyrosine hydroxylase-immunoreactive neurons in the medial amygdaloid nucleus of the Syrian hamster. Brain Res. 575:199-207.

Asmus, S. E. and Newman, S. W. (1993a). Tyrosine hydroxylase neurons in the male hamster chemosensory pathway contain androgen receptors and are influenced by gonadal hormones. J. Comp. Neurol. 331:445-457.

Asmus, S. E. and Newman, S. W. (1993b). Tyrosine hydroxylase mRNA-containing neurons in the medial amygdaloid nucleus and the reticular nucleus of the thalamus in the Syrian hamster. Mol. Brain Res. 20:267-273.
BAUM, M. J. and EvERITT, B. J. (1992). Increased expression of c-fos in the medial preoptic area after mating in male rats: role of afferent inputs from the medial amygdala and midbrain central tegmental field. Neuroscience 50:627-646.

BeACH, F. A. and PAUKer, P. S. (1949). Effects of castration and subsequent androgen administration upon mating behavior in the male hamster (Cricetus auratus). Endocrinology 45:211-221.

BJorkLund, A. and Lindvall, O. (1984). Dopaminecontaining systems in the CNS. In: Handbook of Chemical Neuroanatomy, Vol. 2. Classical Transmitters in the CNS. Part I. A. Bjorklund and T. Hokfelt, Eds. Elsevier, Amsterdam, pp. 55-122.

Bullitt, E. (1990). Expression of c-fos-like protein as a marker of neuronal activity following noxious stimulation in the rat. J. Comp. Neurol. 296:517-530.

Cambi, F., Fung, B., and Chikaraishi, D. (1989). 5' Flanking DNA sequences direct cell-specific expression of rat tyrosine hydroxylase. $J$. Neurochem. 53:1656-1659.

Ceccatelli, S., Villar, M. J., Goldstein, M., and HOKFELT, T. ( 1989). Expression of c-Fos immunoreactivity in transmitter-characterized neurons after stress. Proc. Natl. Acad. Sci. USA 86:9569-9573.

Contreras, R. J., Beckstead, R. M., and Norgren, R. (1982). The central projections of the trigeminal, facial, glossopharyngeal and vagus nerves: an autoradiographic study in the rat. J. Auton. Nerv. Sys. 6:303322.

DAHLSTROM, A. (1968). Effect of colchicine on transport of amine storage granules in sympathetic nerves of rat. Eur. J. Pharmacol. 5:111-113.

Dahlstrom, A. and FuXE, K. (1964). Evidence for the existence of monoamine-containing neurons in the central nervous system. I. Demonstration of monoamines in the cell bodies of brain stem neurons. Acta Physiol. Scand. 62(Suppl. 232):1-55.

DAVIS, B. J. and MACRIDES, F. M. (1983). Tyrosine hydroxylase immunoreactive neurons and fibers in the olfactory system of the hamster. J. Comp. Neurol. 214:427-440.

Dragunow, M. and Robertson, H. A. (1987). Kindling stimulation induces $c$-fos protein( $s$ ) in granule cells of the rat dentate gyrus. Nature 329:441-442.

DragunOw, M. and FAULL, R. (1989). The use of c- fos as a metabolic marker in neuronal pathway tracing. $J$. Neurosci. Meth. 29:261-265.

Dun, N. J., DuN, S. L., and ChiAiA, N. L. ( 1993). Hemorrhage induces Fos immunoreactivity in rat medullary catecholaminergic neurons. Brain Res. 608:223232.

Erlich, M. E., Grillo, M., Joh, T. H., Margolis, F. L., and BAKER, H. (1990). Transneuronal regulation of neuronal specific gene expression in the mouse olfactory bulb. Mol. Brain Res. 7:115-122.

Fiber, J. M., Adames, P., and SwanN, J. M. (1993). Pheromones induce $\mathrm{c}-f o s$ in limbic areas regulating 
male hamster mating behavior. Neuroreport 4:871874.

Fritschy, J. -M., Frondoza, C. G., and Grzanna, R. (1991). Differential effects of reserpine on brainstem catecholaminergic neurons revealed by Fos protein immunohistochemistry. Brain Res. 562:48-56.

GiZang-GinsberG, E. and Ziff, E. B. (1990). Nerve growth factor regulates tyrosine hydroxylase gene transcription through a nucleoprotein complex that contains c-Fos. Genes Dev. 4:477-491.

Gomez, D. M. and Newman, S. W. (1992). Differential projections of the anterior and posterior regions of the medial amygdaloid nucleus in the Syrian hamster. $J$. Comp. Neurol. 317:195-218.

Guthrie, K. M., Anderson, A. J., Leon, M., and GALL, C. (1993). Odor-induced increases in c-fos mRNA expression reveal an anatomical "unit" for odor processing in olfactory bulb. Proc. Natl. Acad. Sci. USA 90:3329-3333.

HAVENS, M. D. and Rose, J. D. (1992). Investigation of familiar and novel chemosensory stimuli by Golden hamster: effects of castration and testosterone replacement. Horm. Behav. 26:505-511.

Herdegen, T., Sandkuhler, J., Gass, P., Kiessling, M., Bravo, R., and Zimmerman, M. (1993). Jun, Fos, Krox, and CREB transcription factor proteins in the rat cortex: basal expression and induction by spreading depression and epileptic seizures. J. Comp. Neurol. 333:271-288.

Hokfelt, T., MARtensson, R., Bjorklund, A., Kleinau, S., and Goldstein, M. (1984). Distributional maps of tyrosine-hydroxylase-immunoreactive neurons in the rat brain. In: Handbook of Chemical Neuroanatomy, Vol. 2. Classical Transmitters in the CNS, Part I. A. Bjorklund and T. Hokfelt, Eds. Elsevier, Amsterdam, pp. 277-379.

Hughes, P., Lawlor, P., and Dragunow, M. (1992). Basal expression of Fos, Fos-related, Jun, and Krox 24 proteins in rat hippocampus. Mol. Brain Res. 13:355357.

Hunt, S. P., Pini, A., and Evan, G. (1987). Induction of $\mathrm{c}$-fos-like protein in spinal cord neurons following sensory stimulation. Nature 328:632-634.

ICARD-Liepkalns, C., Faucon Biguet, N., Vyas, S., Robert, J. J., SAssone-Corsi, P., and Mallet, J. (1992). AP-1 complex and c-fos transcription are involved in TPA provoked and trans-synaptic inductions of the tyrosine hydroxylase gene: insights into long-term regulatory mechanisms. $J$. Neurosci. Res. 32:290-298.

INSEL, T. R. and WITT, D. M. (1991). Activation of c-fos-like protein in PVN oxytocin cells during male sexual behavior. Soc. Neurosci. Abstr. 17:1415.

Kalia, M. and Sullivan, J. M. (1982). Brainstem projections of sensory and motor components of the vagus nerve in the rat. J. Comp. Neurol. 211:248-264.

Kalia, M., Fuxe, K., and Goldstein, M. (1985). Rat medulla oblongata. II. Dopaminergic, noradrenergic
(A1 and A2) and adrenergic neurons, nerve fibers, and presumptive terminal processes. J. Comp. Neurol. 233:308-332.

Kollack, S. S. and Newman, S. W. (1992). Mating behavior induces selective expression of Fos protein within the chemosensory pathways of the male Syrian hamster brain. Neurosci. Lett. 143:223-228.

KoolhaAs, J. M., VAN den BRinK, T. H. C., RoOzenDAAL, B., and BOORSMA, F. (1990). Medial amygdala and aggressive behavior: interaction between testosterone and vasopressin. Aggress. Behav. 16:223-229.

Lehman, M. N., Winans, S. S., and Powers, J. B. (1980). Medial nucleus of the amygdala mediates chemosensory control of male hamster sexual behavior. Science 210:557-560.

LEHMAN, M. N. and Winans, S. S. (1982). Vomeronasal and olfactory pathways to the amygdala controlling male hamster sexual behavior: autoradiographic and behavioral analyses. Brain Res. 240:27-41.

Li, Y. -Q., Takada, M., Shinonaga, Y., and Mizuno, N. (1993). The sites of origin of dopaminergic afferent fibers to the lateral habenular nucleus in the rat. $J$. Comp. Neurol. 333:118-133.

Mitchell, J. B. and Stewart, J. ( 1989). Effects of castration, steroid replacement, and sexual experience on mesolimbic dopamine and sexual behaviors in the male rat. Brain Res. 491:116-127.

Morgan, J. I. and Curran, T. (1991). Stimulus-transcription coupling in the nervous system: involvement of the inducible proto-oncogenes fos and $j u n$. Annu. Rev. Neurosci. 14:421-451.

Morgan, J. I., Cohen, D. R., Hempstead, J. L., and Curran, T. (1987). Mapping patterns of c-fos expression in the central nervous system after seizure. Science 237:192-197.

Morin, L. P. and BlaNCHARD, J. (1993). Organization of the hamster paraventricular hypothalamic nucleus. J. Comp. Neurol. 332:341-357.

Narvaez, J. A., Covenas, R., De Leon, M., Aguirre, J. A., Cintra, A., Goldstein, M., and Fuxe, K. (1993). Induction of c-fos immunoreactivity in tyrosine hydroxylase and phenylethanolamine- $N$-methyltransferase immunoreactive neurons of the medulla oblongata of the rat after phosphate-buffered saline load in the urethane-anaesthetized rat. Brain Res. 602:342-349.

Nitibach, M. N., Schulkin, J., and EPSTein, A. N. (1989). The medial amygdala is part of a mineralocorticoid-sensitive circuit controlling $\mathrm{NaCl}$ intake in the rat. Behav. Brain Res. 35:127-134.

Pezzone, M. A., LeE, W. -S., Hoffman, G. E., and RaBIN, B. S. ( 1992). Induction of c-Fos immunoreactivity in the rat forebrain by conditioned and unconditioned aversive stimuli. Brain Res. 597:41-50.

Pfaus, J. G., Damsma, G., Nomikos, G. G., Wenkstern, D. G., Blaha, C. D., Phillips, A. G., and FIBIGER, H. C. (1990). Sexual behavior enhances cen- 
tral dopamine transmission in the male rat. Brain Res 530:345-348.

Powers, J. B., Bergondy, M. L., and Matochik, J. A. (1985). Male hamster sociosexual behaviors: effects of testosterone and its metabolites. Physiol. Behav. 35:607-616.

Ricardo, J. A. and KoH, E. T. (1978). Anatomical evidence of direct projections from the nucleus of the solitary tract to the hypothalamus, amygdala, and other forebrain structures in the rat. Brain Res. 153:126.

Riche, D., De Pommery, J., and Menetrey, D. (1990). Neuropeptides and catecholamines in efferent projections of the nuclei of the solitary tract in the rat. J. Comp. Neurol. 293:399-424.

Robertson, G. S., Pfaus, J. G., Atkinson, L. J., Matsumura, H., Phillips, A. G., and Fibiger, H. C. (1991). Sexual behavior increases c-fos expression in the forebrain of the male rat. Brain Res. 564:352-357.

SaGar, S. M., Sharp, F. R., and Curran, T. (1988). Expression of c-fos protein in brain: metabolic mapping at the cellular level. Science 240:1328-1331.

SCHULKIN, J., MARINI, J., and EPSTEIN, A. N. ( 1989). A role for the medial region of the amygdala in mineralocorticoid-induced salt hunger. Behav. Neurosci. 103: $178-185$.

Smeyne, R. J., Schilling, K., Rober TSON, L., LuK, D., Oberdick, J., Curran, T., and Morgan, J. I. (1992). Fos-lacZ transgenic mice: mapping sites of gene induction in the central nervous system. Neuron 8:13-23.

Stone, D. M., Wessel, T., Joh, T. H., and Baker, H. (1990). Decrease in tyrosine hydroxylase, but not aromatic L-amino acid decarboxylase, messenger RNA in rat olfactory bulb following neonatal, unilateral odor deprivation. Mol. Brain Res. 8:291-300.

Swanson, L. W. (1987). The hypothalamus. In: Handbook of Chemical Neuroanatomy, Vol. 5. Integrated Systems of the CNS, Part I. A. Bjorklund, T. Hokfelt, and L. W. Swanson, Eds. Elsevier, Amsterdam, pp. $1-124$.

Swanson, L. W., Sawchenko, P. E., Berod, A., Hartman, B. K., Helle, K. B., and Vanorden, D. E. (1981). An immunohistochemical study of the organization of catecholaminergic cells and terminal fields in the paraventricular and supraoptic nuclei of the hypothalamus. I. Comp. Neurol. 196:271-285.

VAN DER KoOY, D., Koda, L. Y., MCGinty, J. F., GerFEN, C. R., and BLOOM, F. E. (1984). The organization of projections from the cortex, amygdala, and hypothalamus to the nucleus of the solitary tract in rat. $J$. Comp. Neurol. 224:1-24.

Van Straaten, F., Muller, R., Curran, T., Van BeVEREN, C., and Verma, I. M. (1983). Complete nucleotide sequence of a human c-onc gene: deduced amino acid sequence of human c- fos protein. Proc. Natl. Acad. Sci. USA 80:3183-3187.

VINCENT, S. R. (1988). Distributions of tyrosine hydroxylase-, dopamine- $\beta$-hydroxylase-, and phenylethanolamine- $N$-methyltransferase-immunoreactive neurons in the brain of the hamster (Mesocricetus auratus). J. Comp. Neurol. 268:584-599.

WARNER, R. K., THOMPSON, J. T., MARKOWSKI, V. P., Loucks, J. A., BAzzeTr, T. J., EATON, R. C., and Hull, E. M. (1991). Microinjection of the dopamine antagonist cis-flupenthixol into the MPOA impairs copulation, penile reflexes and sexual motivation in male rats. Brain Res. 540:177-182.

Wessel, T. C. and JOH, T. H. ( 1992). Parallel upregulation of catecholamine-synthesizing enzymes in the rat brain and adrenal gland: effects of reserpine and correlation with immediate early gene expression. $\mathrm{Mol}$. Brain Res. 15:349-360.

WhitehEAD, M. C. and Frank, M. E. (1983). Anatomy of the gustatory system in the hamster: central projections of the chorda tympani and the lingual nerve. $J$. Comp. Neurol. 220:378-395.

Wolf, M. E., Zigmond, M. J., and Kapatos, G. (1989). Tyrosine hydroxylase content of residual striatal dopamine nerve terminals following 6hydroxydopamine administration: a flow cytometric study. J. Neurochem. 53:879-885.

WoOD, R. I. and Newman, S. W. (1993). Mating activates androgen receptor-containing neurons in chemosensory pathways of the male Syrian hamster brain. Brain Res. 614:65-77.

ZHANG, D. M., EPSTEIN, A. N., and SChulkin, J. (1993). Medial region of the amygdala: involvement in adrenal-steroid-induced salt appetite. Brain Res. 600:20-26. 